\title{
Temporal Changes in Morphological Traits in a Population of Echinacea pallida in the Tall Grass Prairie Preserve, Oklahoma
}

\author{
José Ramón Arévalo $^{*}, 1,2$, Adam Ryburn ${ }^{3}$ and Sonia D. Jaiswal ${ }^{1}$ \\ ${ }^{I}$ Department of Botany, Oklahoma State University, Stillwater 74078, Oklahoma, USA \\ ${ }^{2}$ Departamento de Ecología, Universidad de La Laguna, La Laguna 38206, Tenerife, Spain \\ ${ }^{3}$ University of New York College at Oneonta, Oneonta, NY 13820, USA
}

\begin{abstract}
We analyzed the structure and spatial temporal changes of a population of Echinacea pallida in the Tall Grass Prairie Preserve of Oklahoma. Plants were classified into different categories based on total leaf length and transition probabilities for three periods (1997-1998, 1998-1999, 1999-2000) and were used to determine temporal changes.

The analysis of transition probabilities among different size classes for the three periods allowed us to discriminate the transition probabilities matrices. A univariate spatial analysis of individuals showed significant aggregation for most distances greater than $40 \mathrm{~cm}$; from 0 to $40 \mathrm{~cm}$ the spatial distribution of stems did not differ $(p>0.05)$ from a random distribution. Aggregation increased from year 1 to year 4 of the study period, which seems to be related to an increase in density.Although we did not have a control site, results for both years with previous burning strongly suggest the effect of fire in the population dynamic.
\end{abstract}

Keywords: Conservation, matrix transition, population structure, ripley's K.

\section{INTRODUCTION}

Spatial patterns of individuals are important characteristics of plant communities (Vacek and Lepš 1996; Godron and Forman 1986) and can be used for analysis of species replacement (Horn 1975; Woods 1979; Busing 1996), species regeneration (Condit et al. 1992), or adults-juveniles relationships (He et al. 1997). Also, the spatial distribution of plant individuals is important for the management of natural areas (Moeur 1993). Temporal changes in the spatial distribution of individuals in a population should be considered because they can depend on successional stages after disturbance (Lepš 1990).

Transition matrices are useful tools for demographic studies of organisms with complex life cycles (regeneration processes depending on environmental changes; Gotelli 1991) and are more realistic than others based on logistic regression (Silvertown 1987). Demographic parameters of populations fluctuate with varying environmental conditions resulting in ever changing transition matrices. Understanding the effect of these transition matrix changes on populations is of great value and interest to conservation biologists (Schemske et al. 1994; Floyd and Ranker 1998). Although the use of matrix models has become a very useful tool in analyzing future population changes (Ebert 1999), the importance of the spatio-temporal models variation affecting

*Address correspondence to this author at the Department of Botany, Oklahoma State University, Stillwater 74078, Oklahoma, USA; Tel: +34922318628; Fax: +34922 318311; E-mail: jarevalo@ull.es population structure has only recently been considered (Kalisz and McPeek 1993; Horvitz and Schemske 1995).

Conservation of rare or endangered species requires knowledge of factors affecting the population dynamics of those species (Horvitz and Schemske 1995). As long as a population transition matrix can be derived from the life cycle of a species (Hubbell and Werner 1979), it is possible to infer quantitative demographic data such as rate of population growth or the stages likely to be affected if present conditions persist (Silvertown et al. 1993).

The economic and medicinal significance of Echinacea pallida (Nutt.) Nutt. has indirectly contributed to the rapid decline of wild populations of this plant (Ladd and Oberle 1995). This herbaceous flowering plant it is one of the less common species of the genus Echinacea (McGregor 1968), and is becoming a rare species in many areas of the United States. Many studies on the tallgrass prairie stress the importance of fire and bison grazing on plant species composition and structure favoring regeneration in some cases and in others the stabilization of the population (e.g. Collins 1990; Fahnestock and Knapp 1994; Bartha et al. 1995).

We analyzed the structure of a population of E. pallida in a tallgrass prairie subjected to bison grazing and a natural rate of prescribed fire reinstated since 1993. The study population had been monitored for four years, and had been affected by fall fires (October) prior to the first sampling year (October 1996) and the third year (October 1998). We tested the hypothesis that changes in the structure and spatial distribution of Echinacea's populations are common and that these changes are related to natural disturbances, favoring the conservation and persistence of the population. 


\section{MATERIAL AND METHODS}

\section{Study Site}

The study was conducted in a zone of the Tall Grass Prairie Preserve (TGP) in Osage County, Oklahoma $\left(36^{\circ} 49^{\prime} \mathrm{N}, 96^{\circ} 23^{\prime} \mathrm{W}\right)$ where bisons were present. The preserve encompasses a natural area of approximately 15,800 ha owned and managed by The Nature Conservancy (TNC).

The management program of this preserve is focused to restore a remnant of the tallgrass prairie landscape in Oklahoma (Hamilton 1996). Prescribed burns are conducted throughout the year: dormant spring burns (March-April), late growing season burns (July-September), and dormant fall burns (October-November). Locations are selected for burning according to the fuel load of the vegetation as well as other management decisions as the maintenance of natural rate of fires (1fire/2 years; Hamilton 1996). Weather parameters remained around historic averages for this area during the sampling period. Mean temperature and total precipitation were $15.8^{\circ} \mathrm{C}$ and $1060 \mathrm{~mm}$, respectively, for the study period (Oklahoma Climatological Survey 2002).

\section{The Species}

Echinacea pallida is a new world species and is geographically widespread throughout the eastern half of the United States and parts of Southern Canada (McGregor 1968; Snyder et al. 1994). E. pallida (Nutt.) Nutt, is a herbaceous perennial forb which grows $40-90 \mathrm{~cm}$ tall. The hirsute stems are mostly simple and occasionally branched. This species has alternate leaves about $10-30 \mathrm{~cm}$ in length (McGregor 1977). It is a hemicryptophyte (McGregor 1968) with no vegetative reproduction. The life cycle is that of a polycarpic perennial (Cronquist 1980) and has a long lifespam. It germinates in spring (Snyder et al. 1994), flowering in summer (May - July) and plants of this species have a high survivorship rate (Dickerson, Longren and Hadle 1981). Leaves duration lasts from early spring to autumn, achene maturity is from summer to autumn, and dispersal of achenes is from autumn to winter (Hemmerly 1976). Echinacea pallida has a transient seed bank (Johnson and Anderson 1986).

\section{Sampling Design}

We selected one population of E. pallida located within the preserve where bison grazing and fire have been restored. In this population we selected a $100 \times 100 \mathrm{~m}$ plot. Within this area, we randomly selected five $10 \times 10 \mathrm{~m}$ plots. We monitored the Echinacea population at the individual plant level. The location of each plant was marked by an aluminum tag nailed into the ground and mapped using Cartesian coordinates. For each individual plant, we recorded the following information: number of flowering heads, number of stems, height of each flowering head and stem $(\mathrm{cm})$, number of leaves, and length of each leaf $(\mathrm{cm})$. We considered recruitment as the new individuals that appeared in a sampling and were not present in the previous one (we assumed that dormancy is uncommon in this species). The plots were sampled in June from 1997 to 2000.

\section{Statistical Analysis}

Plants were classified into categories in order to construct transition matrices. We based stage categories on size using the sum of all the leaf lengths as the parameter to discriminate among categories (Table 1a). This is considered a good estimator of the development of the plant (Valverde and Silvertown 1997). In general, plants with a total leaf length less than $25 \mathrm{~cm}$ do not produce flowers (pers. observation). Dormancy was uncommon (plants that grew up after being considered dead the previous year) and affected less than $0.01 \%$ of the total individuals. We used a fixed number of categories in order make comparisons among periods. We were unable to include fecundity in the study. However, use of matrixes allowed us to obtain a picture of the changes in the population structure for the study periods.

Table 1a. Stage Categories Used to Describe the Population Dynamics of Echinacea pallida

\begin{tabular}{|c|c|c|}
\hline Stage & Class & Plant size (*) \\
\hline \hline Pre-reproductive & 1 & $<24.9 \mathrm{~cm}$ \\
\hline Stage 2 & 2 & $25-99.9 \mathrm{~cm}$ \\
\hline Stage 3 & 3 & $100-199.9 \mathrm{~cm}$ \\
\hline Stage 4 & 4 & $200-299.9 \mathrm{~cm}$ \\
\hline Stage 5 & 5 & $>300 \mathrm{~cm}$ \\
\hline${ }^{*}$ ) sum of all leaf length per plant. & &
\end{tabular}

Potential fates of Echinacea pallida in different stages are shown in Table 1b. The transition coefficient a42 indicates the probability of a plant in size class 2 to progress to size class 4 in the next year. A transition probability of a35 indicates the probability of a plant in size class 5 to revert to class 3 during the next year. The information of newly recruited individuals was included next in every coming year in the calculations of the transition matrices. Although we were unable to include fecundity (due to the inability to assign new individuals to the different size classes), the matrix represents the transition of the individuals to either larger classes or regression or remaining in the same class. This information can be visualized easily in a transition matrix.

Table 1b. Potential Fates of Echinacea pallida in a Basic Population Matrix

\begin{tabular}{|c|c|c|c|c|c|}
\hline a11 & a12 & a13 & a14 & a15 & a1d \\
\hline a21 & a22 & a23 & a24 & a25 & a2d \\
\hline a31 & a32 & a33 & a34 & a35 & a3d \\
\hline a41 & a42 & a43 & a44 & a45 & a4d \\
\hline a51 & a52 & a53 & a54 & a55 & a5d \\
\hline
\end{tabular}

We compared the frequency transition matrices from the plots of each period using the Pearson correlation coefficient to test for significant differences in the distribution of individuals at the different stages (for a $\mathrm{p}<0.05$ ). The 
correlation index indicates if the variability in the transition coefficients is either different or not. In the case of non significance, the data of the five plots in each period were pooled to obtain only one matrix for each period (1997-1998, 1998-1999, 1999-2000).

Matrices are stationary if the elements of the transition probability matrices do not change over time (Usher 1992). To test the temporal stationary of the transition matrices (between the three periods analyzed) we used the test of Anderson and Goodman (1957), defined as

$$
-2(\ln \lambda)=2 \sum_{i=1}^{m} \sum_{j=1}^{m} \sum_{t=1}^{T} n_{i j}(t) \ln \left(p_{i j}(t) / p_{i j}\right)
$$

Where $p_{i j}(t)$ is the element of the $\mathrm{i}^{\text {th }}$ row and $\mathrm{j}^{\text {th }}$ column of each matrix and $p_{i j}$ is the element for the average probability matrix value. $-2(\ln \lambda)$ is distributed asymptotically as $\chi^{2}$ with $m(m-1)(T-1)$ degrees of freedom (where $m$ is the number of stages and $T$ the number of series).

We studied the spatial distributions of Echinacea pallida in the five plots for the four different years using the Ripley's univariate $\mathrm{K}_{1}(t)$ function modified by Szwagrzyk (1992). Also, spatial distributions of new individuals (juveniles) of the three years were analyzed. This function determines the consistency of the empirical distribution of distances among individuals with the Poisson expectations (Szwagrzyk and Czerwczak 1990), and is given by the equation:

$$
K_{1}(t)=\frac{v(A)}{n^{2}} \sum_{x \in A} \sum_{y \in A \cup B} 1_{(0, t]}(d(x, y))
$$

In this analysis each analyzed plot was divided into the inner circle (A) and the buffer zone (B), where: $n=$ number of individuals per plot; $v(A)=$ the area of study plot inner circle; $t=$ distance between individuals; $x, y=$ points of the Euclidean distance between points $\mathrm{x}$ and $\mathrm{y}$.

The $K_{1}(t)$ function is transformed into a function $L_{1}(t)$ as follow:

$$
L_{1}(t)=\left(k_{1}(t) / \pi\right)^{0.5}
$$

The buffer zones were included to solve the problem of edges effects (Ripley 1977). To detect departure from complete spatial randomness (CSR), constant approximate confidence intervals were established by accepting the value $\pm 1.42(\mathrm{~A} / \mathrm{n}-1)^{0.5}$ where: $A$ is the area of the inner circle, and $n$ is the number of trees in the plot, as a reasonable approximation of the 5\% significance points (Ripley 1979).

Spatial distribution of individuals of Echinacea pallida was analyzed with the modified univariate $\mathrm{K}_{1}(\mathrm{t})$ function. Transforming $\mathrm{K}_{1}(\mathrm{t})$ to $\mathrm{W}_{\mathrm{k}}$ allowed us to graphically present the results by displaying the pattern across multiple scales. The indicator $\mathrm{W}_{\mathrm{k}}$ was used to estimate the departure of the individual's distribution from CSR (Szwagrzyk 1990) as follows:

$$
W_{k}=\frac{\max _{t}\left(L_{1}(t)-t\right)}{S} * \operatorname{sign}\left(L_{1}(t)-t\right)
$$

where $\max \left(L_{1}(t)-t\right)=$ maximal deviation of the $\mathrm{L}_{1}(\mathrm{t})$ function from CSR; $\mathrm{S}=$ the width of the confidence interval; $\operatorname{sign}\left(\mathrm{L}_{1}(\mathrm{t})-\mathrm{t}\right)=-1.0$, if $\mathrm{L}_{1}(\mathrm{t})-\mathrm{t}<0$; $\operatorname{sign}\left(\mathrm{L}_{1}(\mathrm{t})-\mathrm{t}\right)=1.0$, if $\mathrm{L}_{1}(\mathrm{t})-$ $\mathrm{t}>0$.

Values of $\mathrm{W}_{\mathrm{k}}<-1$ indicate regular distribution of the individuals, while values $>1$ indicate clumped distribution or aggregation. When the spatial distribution of stems at agiven distance do not differ from a random distribution (a Monte Carlo test using 200 iterations of randomly generated $x, y$ coordinates), the value of the curve at that distance was zero. When significant aggregation was detected, the values of the curve were positive and higher than 1 (these values increased depending on the differences among the expected and the observed values). Negative values $<-1$ indicated significant repulsion at the given distance.

To test differences among recruitment, mortality, and number of flower heads in each size class with respect to a given period, we used a two factor analysis of variance (ANOVA, $\mathrm{n}=5, \mathrm{a}=3, p<0.05$ ) for that class and year. In order to determine statistical differences among the groups, we used the post-hoc Tukey test $(p<0.05)$ to detect differences within a given class. Basic statistical methods were performed according to Zar (1984) and were applied using the SPSS statistical package (SPSS 1997).

\section{RESULTS}

At the sampling period, plant cover almost reached $100 \%$ in all plots with occasional rocks or bare soil patches. Differences in the number of individuals, recruitment and mortality were detected. The number of individuals of Echinacea pallida increased in the five plots from 1997 to 1999 and decreased in 2000 (Table 2a). Only two plots showed a decrease in the number of individuals when such number was analyzed plot by plot (Table 2a). Both plots showed the highest density of individuals in 1999. Recruitment rate was higher in 1999 (0.35; Table 2b), than in $1998(0.22)$ and $2000(0.25)$. Mortality (Table 2c) showed a different pattern, with the highest rate of mortality $(0.38)$ in 2000, followed by 1999 with 0.10 and 1998 with 0.01 .

Recruitment (number of individuals recruited from each class) did not differ among periods for size classes 2, 3 and 5. The analysis of classes 1 and 4 revealed significant differences $(p<0.05)$, there was a higher recruitment in class 1 and lower recruitment in class 4 (Fig. 1a) in 1997-1998 than in the others periods. Mortality showed a more distinct pattern, with lower mortality for all classes in 1997-1998 (Fig. 1b). We found no significant differences $(\mathrm{p}>0.05)$ in mortality for class 5 (Fig. 1c). There were higher numbers of flowers $(\mathrm{p}<0.05)$ in 1998 and 2000 with respect to 1999 and 2001 for classes 3, 4 and 5 .

Table 3 shows the transition probability matrices calculated from the pooled data of the five plots. Previously, we determined that the five frequency transition matrices of each period did show significant differences in the coefficient values using the Pearson correlation coefficient; all combinations of matrices for each period were significant $(\mathrm{p}<0.01$ for $\mathrm{n}=25)$. 
Table 2. Echinacea Individual's Density (Individuals/100 $\mathbf{m}^{2}$ ) in the Five Plots Randomly Selected for the Population. a) Density of all Individuals in the Plot. b) Recruitment Density during each Study Period (RR: Recruitment Rate. c) Mortality Density during Period (MR.: Mortality Rate)

\begin{tabular}{|c|c|c|c|c|c|}
\hline a) & Plot & 1997 & 1998 & 1999 & 2000 \\
\hline & 1 & 80 & 147 & 155 & 245 \\
\hline & 2 & 298 & 466 & 719 & 343 \\
\hline & 3 & 26 & 36 & 65 & 78 \\
\hline & 4 & 691 & 762 & 906 & 789 \\
\hline \multirow{2}{*}{\multicolumn{2}{|c|}{5}} & 373 & 449 & 615 & 719 \\
\hline & & 1468 & 1860 & 2460 & 2174 \\
\hline \multirow{8}{*}{\multicolumn{2}{|c|}{ b) }} & Plot & 1997-1998 & 1998-1999 & 1999-2000 \\
\hline & & 1 & 69 & 39 & 126 \\
\hline & & 2 & 173 & 309 & 70 \\
\hline & & 3 & 10 & 32 & 21 \\
\hline & & 4 & 81 & 250 & 127 \\
\hline & & 5 & 80 & 237 & 205 \\
\hline & & Total & 413 & 867 & 549 \\
\hline & & $\mathrm{RR}$ & 0.22 & 0.35 & 0.24 \\
\hline & \multirow[t]{8}{*}{ c) } & Plot & 1997-1998 & 1998-1999 & $1999-2000$ \\
\hline & & 1 & 2 & 31 & 36 \\
\hline & & 2 & 3 & 56 & 446 \\
\hline & & 3 & 0 & 3 & 8 \\
\hline & & 4 & 10 & 106 & 244 \\
\hline & & 5 & 6 & 71 & 101 \\
\hline & & Total & 21 & 267 & 835 \\
\hline & & MR & 0.01 & 0.1 & 0.38 \\
\hline
\end{tabular}

The results for the test of temporal stationary indicated that the transition probability matrix was different for the period 1997-1998 than for that in 1998-1999 [having a $2(\ln \lambda)=1750$, gl: $80, p<0.01]$, but not from for period 1999$2000[-2(\ln \lambda)=-40.5, \mathrm{gl}: 80$, non significant $]$. Also, the period 1998-1999 was significantly different from that in 1999$2000[-2(\ln \lambda)=345, \mathrm{gl}: 80, p<0.01]$. When we compared these results with those obtained during the October prescribed fires, the calculated matrices were different before than after the October prescribe fires.

We represented graphically (Fig. 2) the percentage of transition coefficients that indicated either change or promotion or reversion or death. Coefficients indicated a higher percentage of promotion in the season without the previous October fire (1998-1999), while no change and reversion was detected for the others. It is important to indicate that mortality became very high in the last season.

Table 3. Transition Matrix Coefficients

\begin{tabular}{|c|c|c|c|c|c|}
\hline \multicolumn{6}{|c|}{$1997-1998$} \\
\hline & class1 & class 2 & class3 & class 4 & class5 \\
\hline class 1 & 0.518 & 0.130 & 0.038 & 0.085 & 0.016 \\
\hline class 2 & 0.441 & 0.648 & 0.395 & 0.137 & 0.048 \\
\hline class 3 & 0.021 & 0.182 & 0.421 & 0.385 & 0.339 \\
\hline class 4 & 0.005 & 0.016 & 0.120 & 0.231 & 0.161 \\
\hline class5 & 0.000 & 0.007 & 0.019 & 0.145 & 0.419 \\
\hline \multicolumn{6}{|c|}{ 1998-1999 } \\
\hline & class1 & class 2 & class 3 & class 4 & class5 \\
\hline class1 & 0.181 & 0.023 & 0.011 & 0.010 & 0.000 \\
\hline class 2 & 0.391 & 0.163 & 0.027 & 0.000 & 0.000 \\
\hline class 3 & 0.095 & 0.390 & 0.202 & 0.092 & 0.036 \\
\hline class 4 & 0.038 & 0.162 & 0.286 & 0.112 & 0.073 \\
\hline class5 & 0.014 & 0.091 & 0.390 & 0.724 & 0.836 \\
\hline \multicolumn{6}{|c|}{$1999-2000$} \\
\hline & class1 & class 2 & class3 & class 4 & class5 \\
\hline class 1 & 0.207 & 0.051 & 0.018 & 0.003 & 0.003 \\
\hline class 2 & 0.375 & 0.417 & 0.167 & 0.078 & 0.030 \\
\hline class 3 & 0.014 & 0.139 & 0.305 & 0.201 & 0.105 \\
\hline class 4 & 0.020 & 0.015 & 0.134 & 0.235 & 0.178 \\
\hline class 5 & 0.006 & 0.003 & 0.066 & 0.184 & 0.388 \\
\hline
\end{tabular}

Fig. (3) shows the $W_{k}$ transformation of the univariate Ripley's $\mathrm{K}_{1}$ for individuals of Echinacea pallida during the four study years. The spatial distribution showed a general significant aggregation $\left(\mathrm{W}_{\mathrm{k}}>1, p<0.05\right)$. There was some variation from this general pattern between years and plots: at short distances $(<40 \mathrm{~cm})$ a random spatial distribution was detected in most plots and years. Plot 1 did not show aggregation at any distance in 1997, and plot 2 in 1998 . The analysis revealed a strong aggregation tendency of plot 4 in 1997, and plot 2 in 2000.

Juveniles showed a highly variable spatial distribution between plots and years. In 1998, only plots 1 and 5 showed significant aggregation less than $1 \mathrm{~m}$. In 1999, the general pattern was a significant aggregation (except for plot 1). In 2000 , plot 2 was the only one with a marked aggregation (Fig. 4). The Wt index generally indicated lower aggregation for juveniles than for Echinacea pallida stems. 


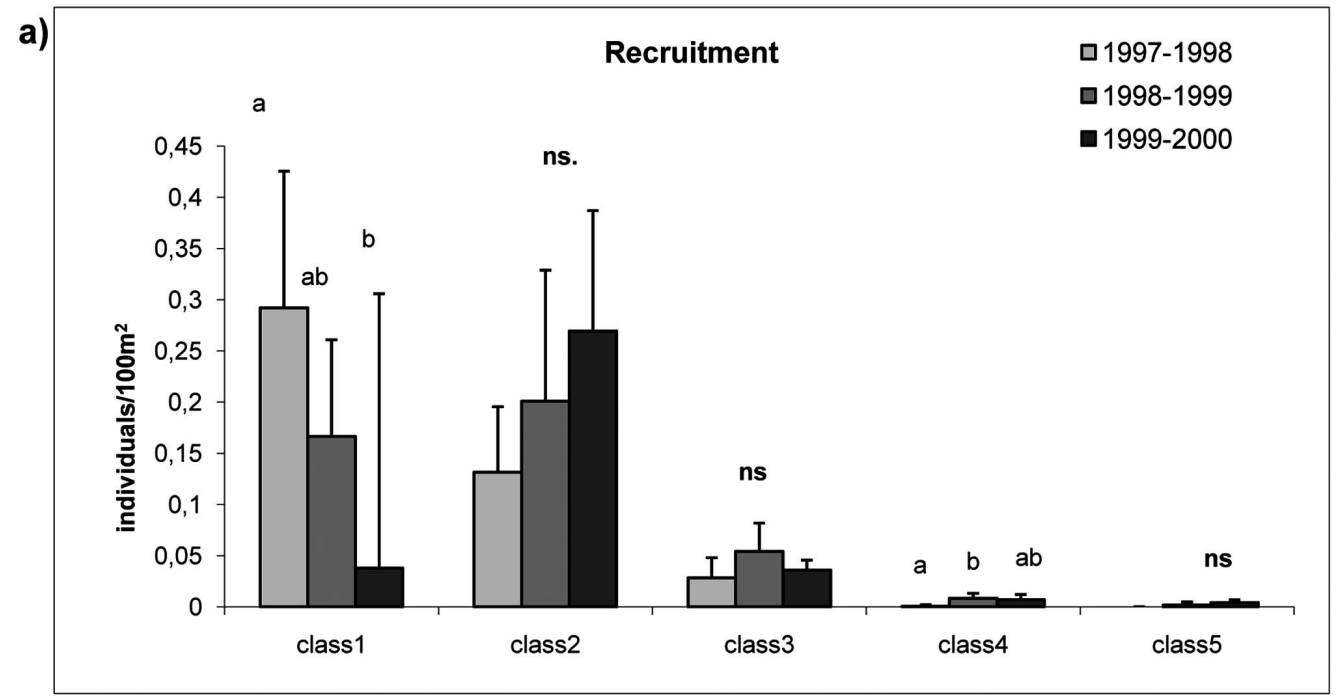

b)

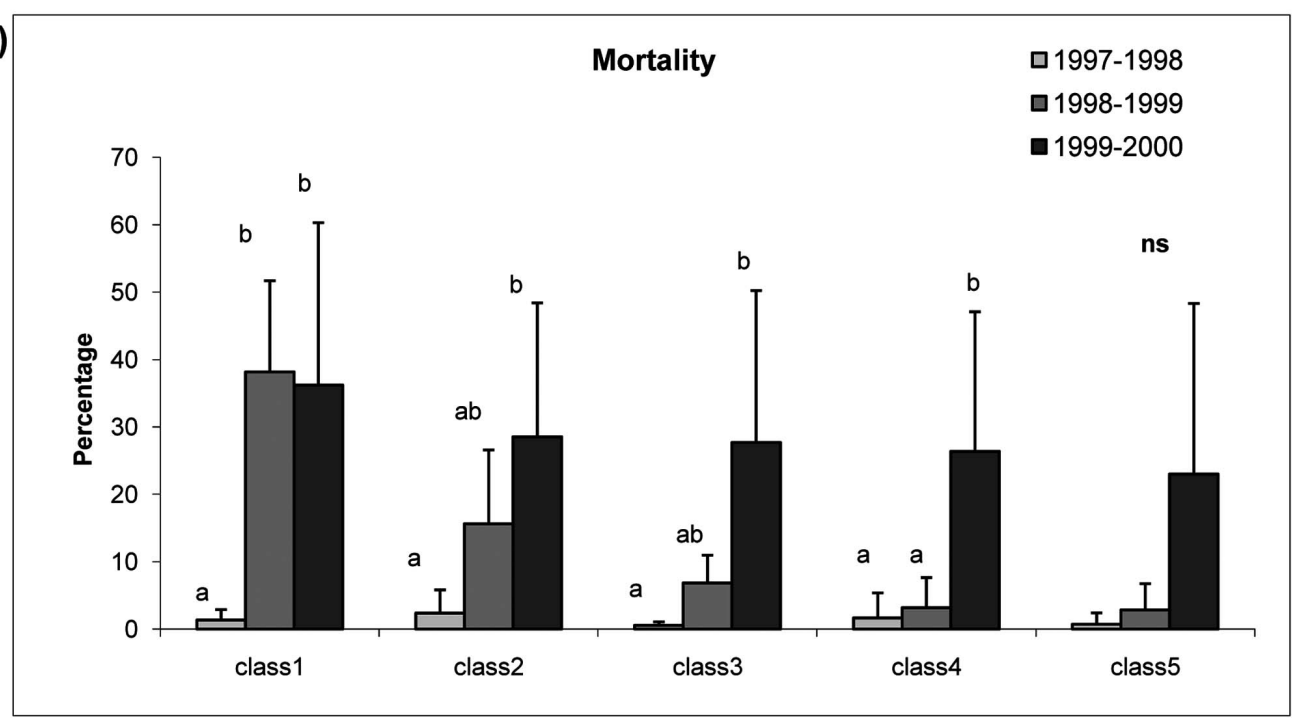

c)

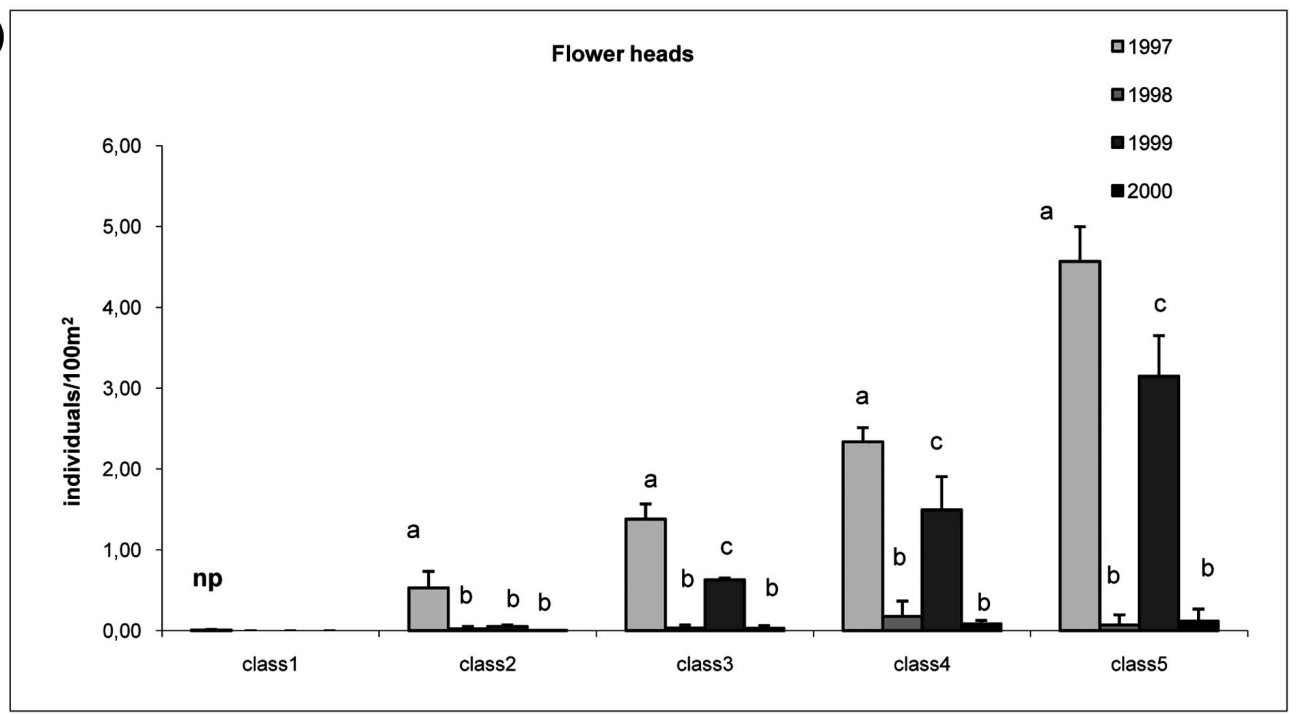

Fig. (1). Population parameters of Echinacea pallida. a) Recruitment, calculated as the number of individuals recruited in each class for the three periods; b) Mortality, calculated as the percentage of individuals of each size class that died from one period to the next, and c) number of flower heads, calculated as the mean number of flowering heads produced per individual of each size class. Identical letters above the bars indicate non-significant differences $(\mathrm{p}>0.05)$. Histograms are the mean $+\mathrm{SD}$ of $\mathrm{n}=5$. 


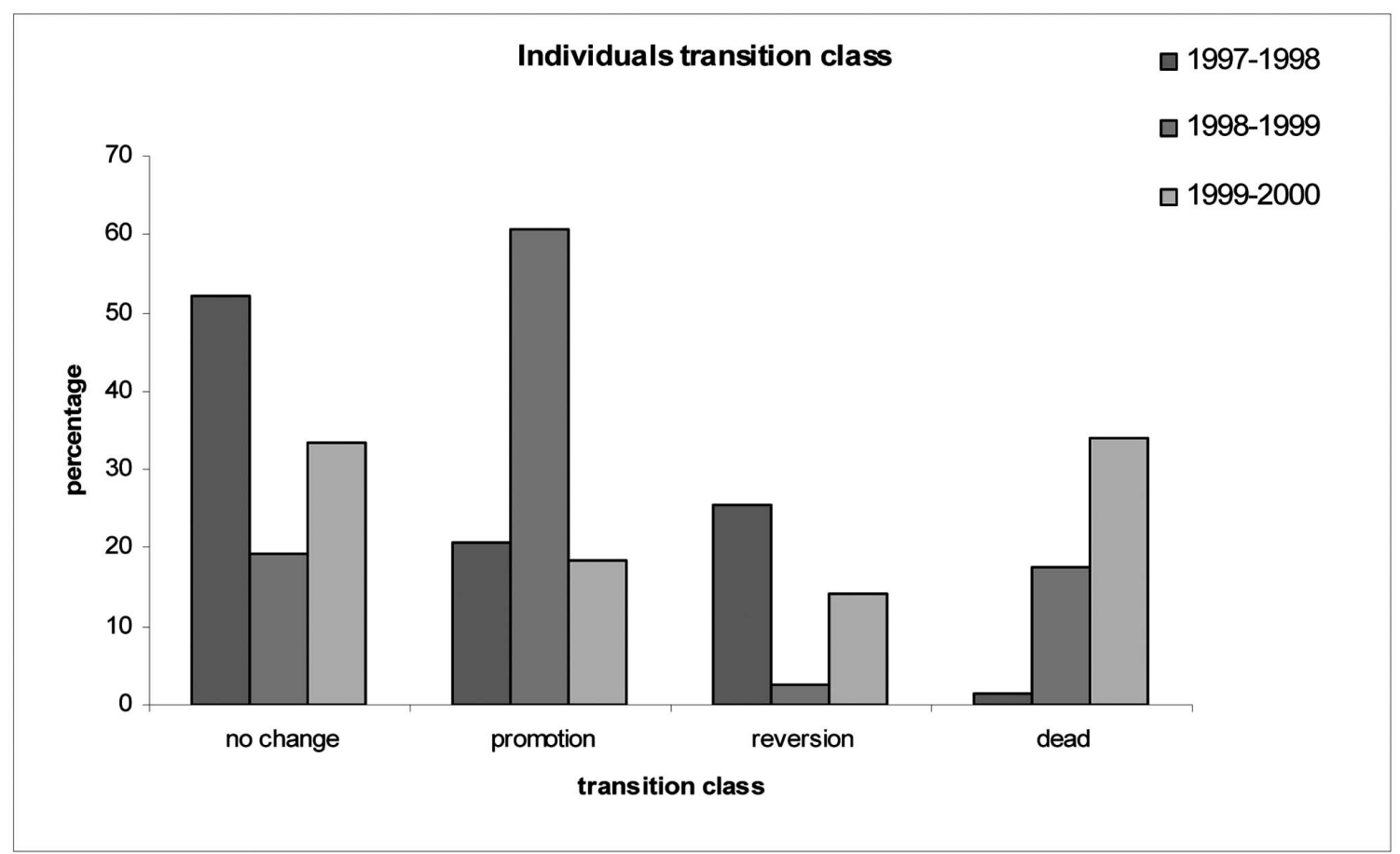

Fig. (2). Percentage of individuals that either progressed or remained or regressed to another class in the three analyzed periods.
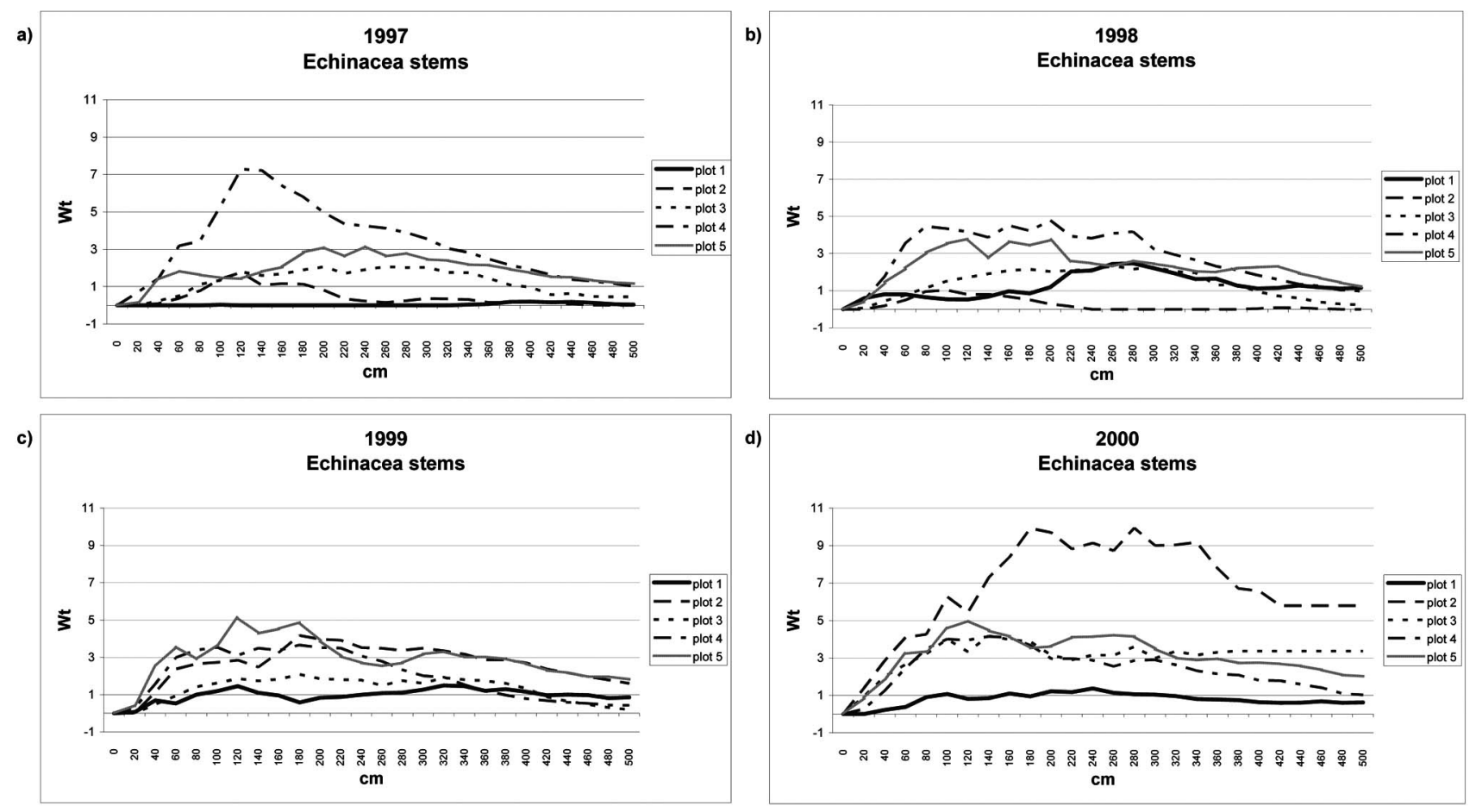

Fig. (3). Values of the $\mathrm{W}_{\mathrm{k}}$ index for all the stems of Echinacea pallida. The index was calculated every $10 \mathrm{~cm}$. Clumped distribution is indicated when $\mathrm{W}_{\mathrm{k}}$ is $>1$. An intermediate distribution between clumped and complete spatial randomness is indicated when $\mathrm{W}_{\mathrm{k}}$ is $<1$ and $>$ 0.333. Significant aggregated distribution is indicated when $\mathrm{W}_{\mathrm{k}}<-1$. An intermediate situation between aggregated and complete spatial randomness is indicated when $\mathrm{W}_{\mathrm{k}}$ is $>-1$ and $<-0.333$.

\section{DISCUSSION}

Our results revealed significant changes in the spatial distribution of the Echinacea pallida population of in the three study periods. Individual's density was very very low in plot 3 with respect the others, but this can be related with environmental variability at the plot level. Recruitment and mortality differed in the three study periods for the different 


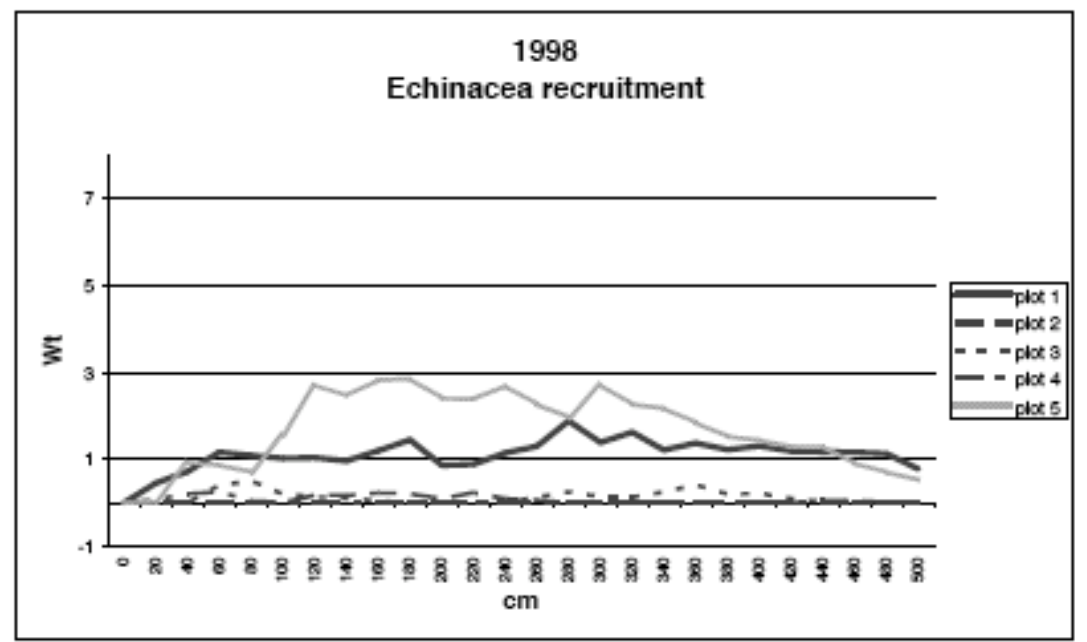

b)
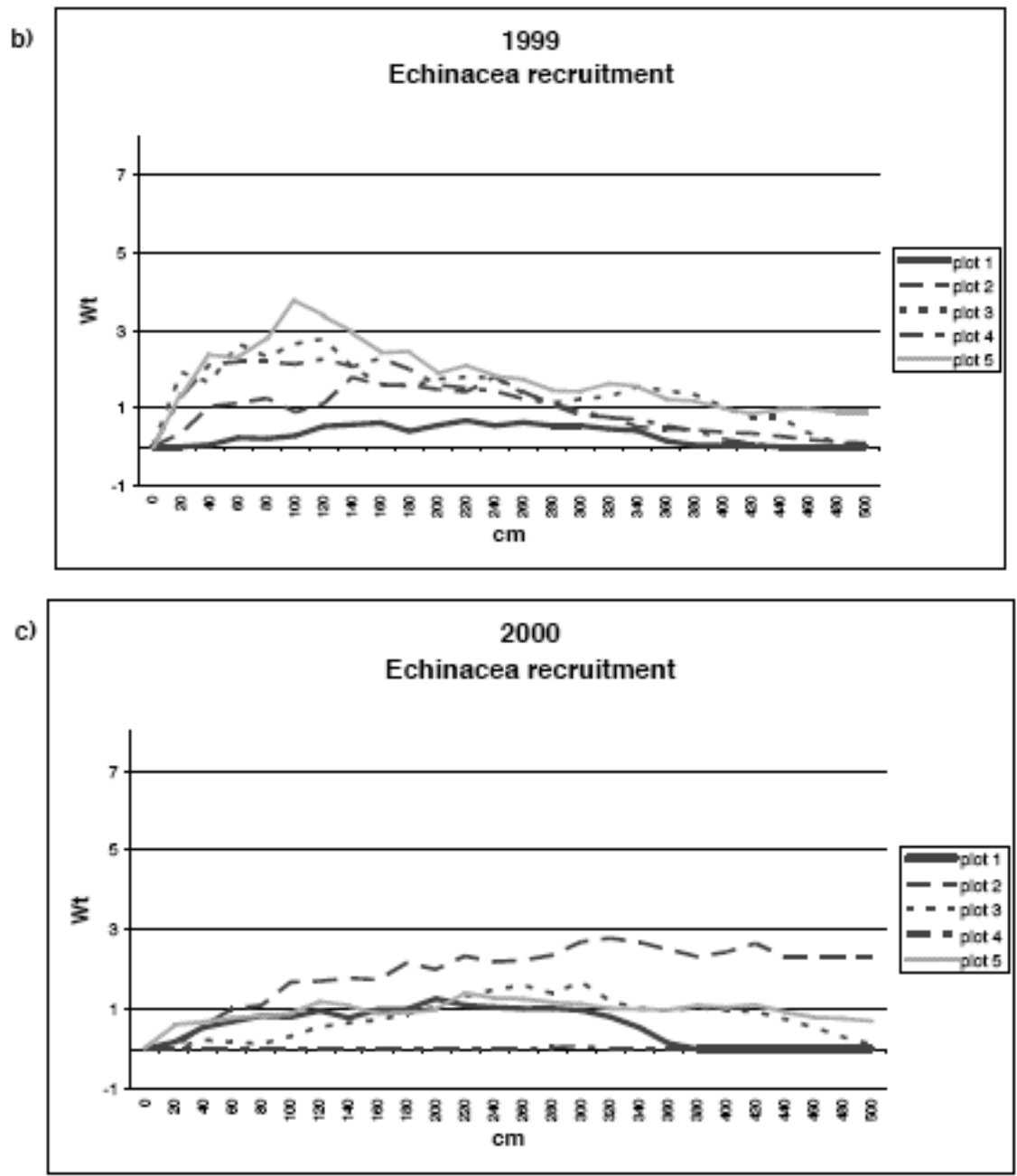

Fig. (4). Values of the $\mathrm{W}_{\mathrm{k}}$ index for recruitment of Echinacea pallid (only new individuals). The index was calculated every $10 \mathrm{~cm}$ (notice the different scales in graphs with respect to Fig. (3)). Again, significant aggregated distribution is indicated when $\mathrm{W}_{\mathrm{k}}<-1$. An intermediate situation between aggregated and complete spatial randomness is indicated when $\mathrm{W}_{\mathrm{k}}$ is $>-1$ and $<-0.333$.

size classes. Recruitment was significantly higher in the first period for class one; at the same time, mortality was significantly lower (mortality showed similar patterns in all size classes). Several studies have reported the importance of fire in the recruitment and mortality of some prairie species populations (Hulburt 1999; Vickery 2002). However, the number of flower heads per individual in each class suggested a strong relationship with the fall fires in the four study years; results were significantly higher for all classes in the year after the fall fire prescription (except the first one which is considered a pre-reproductive stage) (Fig. 1c). 
Transition matrices did not show significant differences when comparing 1997-1998 and 1999-2000. However, significant differences were found when comparison was made with the period 1998-1999. We suggest that fall fire had an important effect in the transition coefficients, and that Echinacea pallida follows a dynamic response to fire: it produces a high number of flowering heads (using the high nutrient availability after fire) but it either reverts or remains in the same class.

Although the effects of fire have been extensively studied in the reproductive dynamics of prairie plants (Dudley and Lajtha 1993; Hamilton 1996; Vickery 2002) particularly with respect to plant survival (Maret and Wilson 2000), reversion of plant size is not a common response. We only had two fire seasons and one non-fire season, and only four years of sampling in our study. However, results suggest that a regular rate of fire is an essential feature for the population dynamics of E. pallida. It allows the maintenance of a stable population. The spatial analysis indicated the same direction of changes. The spatial analysis of Echinacea pallida stems revealed a tendency for a significant aggregation in almost all plots and years. Aggregation at different distances should be related with the prevalence of favorable microsites, such as areas with low rock cover or higher humidity. Environmental micro-heterogeneity is an important factor in determining the spatial distribution of plants (Manabe and Yamamoto 1997). However, spatial distribution at short distances $(20$ to $40 \mathrm{~cm}$ ) showed a random distribution.

Leaves of Echinacea can be $40 \mathrm{~cm}$ long; thus, individuals growing at less than $30 \mathrm{~cm}$ from each other may be subject to mutual shadowing; these areas will eventually have negative consequences for plant establishment.

Plant aggregation became more important from 1997 to 2000. This is more likely related with the increase of individual plants in the population.

Juvenile plants showed similar patterns, except for years 1998 and 2000, when no significant aggregation was detected below $100 \mathrm{~cm}$ distance among plants. In 1999, aggregation started at $20 \mathrm{~cm}$ (Fig. 4), and it was stronger for juveniles with respect to other years. Recruitment presented the highest rate during that year also (Table 2), corresponding to the year previous to the prescribed burning (in opposition to the other two study years). Fire opens spaces and increases soil nutrients, allowing for a more aggregated population at short distances. Carbon investment goes to the establishment of new individuals neither than to growth of the individuals already present.

Although we only analyzed one large population and the conclusions cannot be extrapolated without further studies, these results are consistent. We can suggest from the studied period that if current management practices are maintained in the preserve, this population of E. pallida will present a stable population structure; it will invest energy in the production of flowers heads after an October fire and in the growth of individuals when years are not preceded by it.

\section{ACKNOWLEDGEMENTS}

We thank the kind staff of the Tallgrass Prairie Preserve and the Nature Conservancy for use of their facilities and support of the project. We also thank the referees and the associate editor Dr. Carlos Busso, whose comments greatly increased the quality of the manuscript.

\section{REFERENCES}

Anderson, TW \& Goodman, LA (1957) Statistical inference about Markov Chains. Annals of Mathematical Statistics, 28, 89-110.

Bartha, S, Collins, SL, Glenn, SM \& Kert, M (1995) Fine scale spatial organization of tallgrass prairie vegetation along a topographic gradient. Folia Geobotanica and Phytotaxonomica, 30 169-84.

Busing, RT (1996) Estimation of tree replacement in an Appalachian PiceaAbies forest. Journal of Vegetation Science, 7, 685-94.

Collins, SL \& Klahr, SC (1991) Tree dispersion in oak-dominated forest along an environmental gradient. Oecologia, 86, 471-77.

Condit, R, Hubbell, SP \& Foster, RB (1992) Recruitment near conspecific adults and the maintenance of tree and shrub diversity in a neotropical forest. American Naturalist, 140, 261-86.

Cronquist, A (1980) Vascular flora of the southeastern United States, volume I. Asteracea. The University of North Carolina Press, Chapel Hill.

Dickerson, JA, Longren, WG \& Hadle, EK (1981) In: Stuckey, R, Reese, KJ (Eds) The prairie peninsula - in the shadow of Transeau. Proceedings of the sixth North American Prairie Conference. The Ohio State University, Columbus, 218-22.

Dudley, JL \& Lajtha, K (1993) Effects of prescribed burning on nutrient availability and primary production in sandplain grasslands. American Midland Naturalist, 130, 286-98.

Ebert, TA (1999) Plant and animal populations. Methods in demography. Academic Press. London.

Fahnestock, JT \& Knapp, AK (1994) Plant responses to selective grazing by bison: Interactions between light, herbivory and water stress Vegetatio, 72, 175-85.

Floyd, SK \& Ranker, TA (1998) Analysis of a transition matrix model for Gaura neomexicana ssp. coloradensis (Onagraceae) reveals spatial and temporal demographic variability. International Journal of Plant Science, 159, 853-63.

Godron, M \& Forman RTT (1986) Landscape Ecology. John Wiley and Sons, NY.

Gotelli, NJ (1991) Metapopulation models: the rescue effect, the propagule rain, and the core-satellite hypothesis. American Naturalist, 138, 768-76.

Hamilton, RG (1996) Using fire and bison to restore a functional tallgrass prairie landscape. Transcript of the 61st North American Wildlife and Natural Resource Conference: 208-14.

He, F, Legendre, P \& Lafrankie, JV (1997) Distribution patterns of tree species in a Malaysian tropical rain forest. Journal of Vegetation Science, 8, 105-14.

Hemmerly, TE (1976) Life cycle strategy of a highly endemic cedar glade species: Echinacea tennesseensis (Compositae). Ph. D. dissertation, Vanderbilt University, Nashville, Tennessee.

Horn, HS (1975) In: Cody, ML \& Diamond, J (Eds.) Ecology and Evolution of Communities, Belknap Press, Cambridge, Massachusetts. 196211.

Horvitz, CC \& Schemske, DK (1995) Spatiotemporal variation in demographic transitions of a tropical understory herb: projection matrix analysis. Ecological Monographs, 65, 155-92.

Hubbell, SP \& Werner, PA (1979) On measuring the intrinsic rate of increase of populations with heterogeneous life histories. American Naturalist, 113, 277-93.

Hulburt, DP (1999) Population ecology and economic botany of Echinacea angustifolia. A native prairie medicinal plant. Ph. D. Dissertation. University of Kansas. Manhattan.

Johnson, RG \& Anderson, RC (1986) The seed bank of a tallgrass prairie in Illinois. American Midland Naturalist, 115, 123-30.

Kalisz, S \& McPeek, MA (1993) Extinction dynamics, population growth and seed banks: and example using an age-structure annual. Oecologia, 95, 314-20.

Ladd, D \& Oberle, F (1995) Tallgrass prairie wildflowers. Falcon Publishing Inc., Helena, Montana.

Lepš, J (1990) In: Krahulec, FL, Agnew, S \& Willens HJ (Eds) Spatial processes in Plant Communities, Academic Publ., The Hague. 7182. 
Manabe, T \& Yamamoto, SI (1997) Spatial distribution of Eurya japonica in an old-growth evergreen broad-leaved forest, SW Japan. Journal of Vegetation Science, 8, 761-72.

Maret, MP \& Wilson, MV (2000) Fire and seedling population dynamics in Western Oregon prairies. Journal of Vegetation Science, 11, 30714.

Moeur, M (1993) Characterizing spatial patterns of trees using stem-mapped data. Forest Science, 39, 756-75.

McGregor, RL (1968) The taxonomy of the genus Echinacea (Compositae). University of Kansas Science Bulletin, 48, 113-42.

McGregor, RL (1977) Atlas of the flora of the Great Plains. University of Kansas Press, Lawrence.

Oklahoma Climatological Survey (2002) Mesonet Climatological Data Summary: FORA. University of Oklahoma. Norman, OK.

Ripley, BD (1977) Modelling spatial patterns. Journal of the Royal Statistical Society, 39, 172-212.

Ripley, BD (1979) Test of randomnes for spatial point patterns. Journal of the Royal Statistical Society B, 41,368-74

Schemske, DW, Husband, BC, Ruckelshaus, MH, Goodewillie, C, Parker, IM \& Bishop, JG (1994) Evaluating approaches to the conservation of rare and endangered plants. Ecology, 75, 584-606.

Silvertown, J (1987) Introduction to plant population ecology. Longman Scientific and Technical. Essex.

Silvertown, J, Franco, M, Pisanty, I \& Mendoze A (1993) Comparative plant demography: relative importance of life cycle components to the finite rate of increase in woody and herbaceous perennials. Journal of Ecology, 81, 465-76.
Snyder, KM, Baskin, JM \& Baskin, CC (1994) Comparative ecology of the narrow endemic Echinacea tennesseensis and two geographically widespread congeners - Relative competitive ability and growth characteristics. International Journal of Plant Sciences, 155, 57-65.

SPSS (1997) SPSS Base 7.5 applications guide / SPSS Inc. Chicago, IL.

Szwagrzyk, J (1990) Regeneration of forest related to the spatial structure of trees: A study of two forest communities in Western Carpathians, southern Poland. Vegetatio, 89, 11-22.

Szwagrzyk, J (1992) Small scale spatial patterns of trees in a mixed Pinus sylvestris - Fagus sylvatica forest. Forest Ecology and Management, 51, 469-76.

Usher, MB (1992) In: Glenn-Lewin, DC, Peet, RK \& Veblen, TT (Eds) Plant succession. Theory and prediction. Chapman and Hall, London. 215-45.

Vacek, S \& Lepš, J (1996) Spatial dynamics of forest decline: the role of neighboring trees. Journal of Vegetation Science, 7, 789-98.

Valverde, T \& Silvertown, J (1997) A metapopulation model for Primula vulgaris, a temperate forest understory herb. Journal of Ecology, $85,193-210$.

Vickery, P (2002) Effects of prescribed fire on the reproductive ecology of northern blazing $\mathrm{h}$ star Liatris scariosa var. noavae-angliae. American Midland Naturalist, 148, 20-7.

Woods, KD (1979) Reciprocal replacement and the maintenance of codominance in a beech-maple forest. Oikos, 33, 31-9.

Zar, JH (1984) Biostatistical analysis. 2nd ed. Prentice-Hall, Englewood Cliffs, NJ.

(C) Arévalo et al.; Licensee Bentham Open.

This is an open access article licensed under the terms of the Creative Commons Attribution Non-Commercial License (http://creativecommons.org/licenses/bync/3.0/), which permits unrestricted, non-commercial use, distribution \& reproduction in any medium, provided the work is properly cited. 